\title{
Study of uncorrected refractory error, cataract and selected diseases of eye in urban and rural area near Chennai, Tamil Nadu
}

\author{
Ashrof Raja', Shib Sekhar Datta², Abhijit V Boratne², J Jahnavi ${ }^{3}$, Rajesh K Konduru4 \\ and Christina Mary P Paul ${ }^{5}$
}

\begin{abstract}
${ }^{1}$ Assistant Professor, ${ }^{3}$ Professor and Head; Department of Community Medicine, Madha Medical College and Hospital, Chennai ${ }^{2}$ Assistant Professor, Department of Community Medicine, Mahatma Gandhi Medical College and Research Institute, Puducherry ${ }^{4}$ Assistant Professor, Department of Community Medicine, PES Institute of Medical Sciences and Research, Kuppam ${ }^{5}$ Assistant Professor, Department of Community Medicine, A.C.S. Medical College and Hospital, Chennai Place of work: Sri Ramachandra Medical College and Research Institute, Chennai
\end{abstract}

\section{A BSTRACT}

Background: Uncorrected refractory error and cataract are leading causes of preventable blindness in India. Objectives: To estimate prevalence and risk factors associated with uncorrected refractory error, cataract and selected eye diseases in urban and rural area near Chennai, Tamil Nadu. Methods: The present cross-sectional study was conducted in urban and rural areas near Chennai during May-August 2009. EPI 30-cluster sampling method was used and individuals in age group 5-70 years were selected with 450 subjects in both areas. Detail ophthalmic examination was done and socio-economic history for risk factors was obtained by trained interviewer. Data was analysed using SPSS version 15.0 software. To compare data sets chi-square test was used and Odds ratios calculated to assess association of risk factor. Results: $33.3 \%$ of the rural population had uncorrected refractory error as compared to $22.2 \%$ urban population $(p<0.001) ; 24.2 \%$ rural population were having cataract compared to $13.1 \%$ urban population $(p<0.001)$. Prevalence of pterygium and external hordeolum were $3 \%$ and $1 \%$ among total study population. Prevalence of internal hordeolum, corneal opacity and blepharitis were less than $1 \%$. Subjects residing in rural area with low standard of living and using wood or cow-dung as cooking fuel were at significant higher risk of developing cataract (OR:2.43 and 2.88 respectively). They were also at significant higher risk of having refractory error (OR: 2.35 for low standard of living and 2.08 for wood or cow-dung as cooking fuel). Conclusion: Prevalence of uncorrected refractory error and cataract was high especially in rural area in the present study.

Keywords: Cataract, eye diseases, uncorrected refractory error

\section{INTRODUCTION}

Blindness is not only a health problem but one of the most important social problems worldwide with enormous economic implications. The global burden of

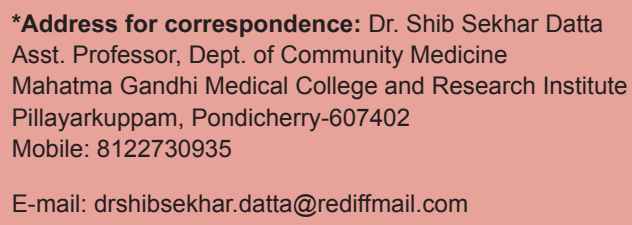

DOI: 10.5530/ijmedph.2.3.3 blind people will grow to 75 million by the year 2020 unless special efforts are taken. ${ }^{1}$ Every five seconds one person in the world goes blind and a child goes blind every minute. ${ }^{2}$ Diseases of the anterior segment like cataract, refractory error and corneal opacity are the leading causes of blindness in the world and the most common causes of preventable blindness in India. ${ }^{3}$ Cataract was identified as the top most cause of preventable blindness in more than $70 \%$ of the cases in India, ${ }^{3,4}$ next is the refractory error which ranks the second important cause of preventable blindness in India, especially in rural areas. ${ }^{5}$ In India there are an estimated 12 million blind people, of which over $90 \%$ live in rural areas. 


\section{OBJECTIVES}

1. To estimate prevalence of uncorrected refractory error, cataract and selected eye problems in urban and rural area near Chennai, Tamil Nadu.

2. To assess various risk factors associated with uncorrected refractory error and cataract in the study area.

\section{MATERIAL AND METHODS}

STUDY SETTING: The community based cross-sectional study was conducted in both urban and rural areas near Chennai, Tamil Nadu during May-August 2009. Alandur municipality of Kancheepuram district with a total population of 146287 was selected as urban area and Poonamallee block of Thiruvallur district with total population of 172300 was selected as rural area for the study purpose. Individuals in the age group 5-70 years were targeted as study subjects.

SAMPLING AND DATA COLLECTION: The EPI 30-cluster sampling method was used to select the study subjects from both urban and rural area. Based on literature from 'Moderate visual impairment in India', ${ }^{6}$ the prevalence of cataract of $40 \%$ was used for sample size calculation. With limit of precision taken as $16 \%$, the sample size obtained was 450. 30-clusters were selected by probability proportionate to size (PPS) method and 15 individuals were selected from each cluster to obtain the sample of 450 individuals in both the areas. After brief introduction regarding purpose of the study and obtaining informed consent, relevant information about family, and household environmental condition was obtained using a pre-tested structured questionnaire by a trained interviewer. It took nearly 30 minutes to complete the interview and examination per person.

OCULAR EXAMINATION: Torch light examination was done on both the eyes to assess presence of any lens opacity as cataract. 'Snellen's chart' was used to observe presence of any refractory error. Torch light and bright daylight examination was also carried out to find out presence of pterygium, blepharitis, external and internal hordeolum and corneal opacity in the study subjects by trained ophthalmic assistant.

DATA ANALYSIS: Data was entered and analysed using Statistical Package for the Social Sciences for Windows (SPSS Inc., Chicago, Illinois, USA) software version 15.0. To compare data sets chi-square test was used (Yates' correction applied wherever applicable) and $p<0.05$ was considered statistically significant. Odds ratios (ORs) with
95\% Confidence Intervals (CIs) were calculated to find out the association of risk factor.

ETHICAL CONSIDERATION: Permission to conduct the field based study was obtained from Institutional Ethical Committee, Sri Ramachandra Medical College and Research Institute, Chennai. Verbal informed consent was obtained from each study subjects before data collection and ocular examination. Subjects requiring ophthalmic consultation were guided for further management as and when required.

\section{RESULTS}

BACKGROUND CHARACTERISTICS OF STUDY POPULATION: Majority $(63.8 \%)$ of the study population belonged to age group 15-45 years. $44.1 \%$ subjects were male and $55.9 \%$ were females. $95.3 \%$ urban population belonged to families with medium or high standard of living as compared to $84.9 \%$ rural population. $85.3 \%$ urban population were literate compared to $75.3 \%$ rural counterpart. $94 \%$ urban population were using LPG gas as cooking fuel compared to $77.1 \%$ rural population. Urban-rural difference in respect to standard of living, education and type of cooking fuel used was statistically highly significant ( $p<0.001$ ). $39.7 \%$ and $26 \%$ of the total study population were known diabetic and hypertensive and $92.9 \%$ were exposed to television. $72.4 \%$ urban population were exposed to computer screen as compared to $51.6 \%$ rural population $(\mathrm{p}<0.001)$. (Table 1$)$

PREVALENCE OF SELECTED EYE DISEASES: In the present study, $33.3 \%$ of the rural study population had uncorrected refractory error as compared to $22.2 \%$ urban population $(\mathrm{p}<0.001)$; and $24.2 \%$ rural population were having cataract compared to $13.1 \%$ urban population $(\mathrm{p}<0.001)$. Prevalence of Pterygium and external hordeolum were $3 \%$ and $1 \%$ respectively among total study population. Prevalence of internal hordeolum, corneal opacity and Blepharitis were less than $1 \%$ among all study subjects. (Table 2 )

\section{RISK FACTORS FOR CATARACT AND UNCORRECTED} REFRACTORY ERROR: Subjects residing in rural area with low standard of living and using wood or cow-dung as cooking fuel were at significant higher risk of having cataract (OR:2.43; CI:1.07-5.61, $\mathrm{p}=0.02$ and OR: 2.88, CI: $1.36-6.14, p=0.002$ respectively). They were also at significant higher risk of having refractory error (OR: 2.35; CI: $1.17-4.76, \mathrm{p}=0.009$ for low standard of living and OR: 2.08; CI: 1.01-4.33, $\mathrm{p}=0.031$ for using wood 


\begin{tabular}{|c|c|c|c|c|}
\hline Characteristics & Total $\mathrm{N}=900$ & Urban $\mathrm{N}=450$ & Rural $\mathbf{N}=450$ & Chi square value [p value] \\
\hline \multicolumn{5}{|l|}{ Age in years } \\
\hline Upto 15 & $74(8.2)$ & $35(7.8)$ & $39(8.7)$ & \multirow{4}{*}{$\begin{array}{c}7.33 \\
{[0.062]}\end{array}$} \\
\hline $15-45$ & $574(63.8)$ & $306(68)$ & $268(59.5)$ & \\
\hline $46-60$ & $211(23.4)$ & $91(20.2)$ & $120(26.7)$ & \\
\hline More than 60 & $41(4.6)$ & $18(4)$ & $23(5.1)$ & \\
\hline \multicolumn{5}{|l|}{ Sex } \\
\hline Male & $397(44.1)$ & $191(42.4)$ & $206(45.8)$ & 1.01 \\
\hline Female & $503(55.9)$ & $259(57.6)$ & $244(54.2)$ & {$[0.314]$} \\
\hline \multicolumn{5}{|l|}{ Standard of living } \\
\hline Medium/High & $811(90.1)$ & $429(95.3)$ & $382(84.9)$ & 27.54 \\
\hline Low & $89(9.9)$ & $21(4.7)$ & $68(15.1)$ & {$[<0.001]$} \\
\hline \multicolumn{5}{|l|}{ Education } \\
\hline Literate & $723(80.3)$ & $384(85.3)$ & $339(75.3)$ & 14.24 \\
\hline Illiterate & $177(19.7)$ & $66(14.7)$ & $111(24.7)$ & {$[<0.001]$} \\
\hline \multicolumn{5}{|l|}{ Cooking fuel used } \\
\hline Gas & $770(85.6)$ & $423(94)$ & $347(77.1)$ & 51.93 \\
\hline Wood/Cow-dung & $130(14.4)$ & $27(6)$ & $103(22.9)$ & {$[<0.001]$} \\
\hline Known diabetic & 357 (39.7) & $182(40.4)$ & $175(38.9)$ & $\begin{array}{c}0.23 \\
{[0.633]}\end{array}$ \\
\hline Known hypertensive & $234(26)$ & $124(27.6)$ & $110(24.4)$ & $\begin{array}{c}1.13 \\
{[0.287]}\end{array}$ \\
\hline Exposure to television & $836(92.9)$ & $421(93.6)$ & $415(92.2)$ & $\begin{array}{c}0.61 \\
{[0.437]}\end{array}$ \\
\hline Exposure to computer screen & $558(62)$ & $326(72.4)$ & $232(51.6)$ & $\begin{array}{c}41.67 \\
{[<0.001]}\end{array}$ \\
\hline
\end{tabular}

(Figures in parenthesis indicate percentages)

\begin{tabular}{lcccc}
\multicolumn{4}{l}{ Table 2: Prevalence of uncorrected refractory error, cataract and other selected eye diseases among study population } \\
\hline Characteristics & Total $\mathbf{N}=\mathbf{9 0 0}$ & Urban $\mathbf{N = 4 5 0}$ & Rural $\mathbf{N}=\mathbf{4 5 0}$ & Chi square value [p value] \\
\hline Uncorrected refractory error & $250(27.8)$ & $100(22.2)$ & $150(33.3)$ & $13.85[<\mathbf{0 . 0 0 1 ]}$ \\
Cataract & $168(18.7)$ & $59(13.1)$ & $109(24.2)$ & $18.30[<0.001]$ \\
Pterygium & $27(3)$ & $16(3.6)$ & $11(2.4)$ & $0.95[0.329]$ \\
External hordeolum & $9(1)$ & $1(0.2)$ & $8(1.8)$ & $4.04^{*}[\mathbf{0 . 0 4 4}]$ \\
Internal hordeolum & $6(0.7)$ & $4(0.9)$ & $2(0.4)$ & $0.17^{*}[0.682]$ \\
Corneal opacity & $4(0.4)$ & - & $4(0.9)$ & $\mathrm{NA}$ \\
Blepharitis & $3(0.3)$ & - & $3(0.7)$ & $\mathrm{NA}$
\end{tabular}

(Figures in parenthesis indicate percentages)

*Yates' corrected

or cow-dung as cooking fuel respectively). There was no significant difference or association between age, sex and known diabetic status in respect to cataract or uncorrected refractory error in rural or urban area. (Table 3)

\section{DISCUSSION}

Present study has revealed that the prevalence of cataract, refractory error, external hordeolum, blepharitis and corneal opacity was more among rural population than urban population. Study subjects were also exposed significantly to the risk factors of eye diseases like low standard of living, harmful cooking fuel, exposure to television, computers and with high prevalence of diabetes and hypertension, and possibly not seeking health care services properly. Study conducted by Haq et al (2009) showed $16.2 \%$ prevalence of cataract in urban India, ${ }^{7}$ which is almost similar to the prevalence of cataract in present study (13.1\%).

Current study showed prevalence of cataract among wood or cow-dung fuel users as $25.4 \%$ and $49.5 \%$ respectively in urban and rural area, and study done by Haq et al (2009) showed $24.9 \%$ cataract prevalence for the people using wood fuel. ${ }^{7}$ Study conducted by Thulasiraj et al (2003) at Aravind Eye Hospital, South India showed that age related cataract was the most common potentially reversible blinding disorder which is about $72 \%$ in rural south India ${ }^{8}$ and present study showed the prevalence of cataract in rural population as $24.2 \%$ which is less compared to the study done by Thulasiraj et al, 


\begin{tabular}{|c|c|c|c|c|}
\hline \multirow{2}{*}{ Characteristics } & \multicolumn{4}{|c|}{ Cataract } \\
\hline & Urban $\mathrm{N}=59$ & Rural N=109 & OR $[95 \% \mathrm{Cl}]$ & Chi square value [p value] \\
\hline \multicolumn{5}{|l|}{ Age in years } \\
\hline Upto 45 & $1(1.7)$ & $6(5.5)$ & 1 & 1.70 \\
\hline $46-60$ & $44(74.6)$ & $82(75.2)$ & $0.31[0.01-2.75]$ & {$[0.427]$} \\
\hline More than 60 & $14(23.7)$ & $21(19.3)$ & $0.25[0.01-2.58]$ & \\
\hline \multicolumn{5}{|l|}{ Sex } \\
\hline Male & $18(30.5)$ & $44(40.4)$ & 1 & 1.60 \\
\hline Female & $41(69.5)$ & $65(59.6)$ & $0.65[0.31-1.34]$ & {$[0.206]$} \\
\hline \multicolumn{5}{|l|}{ Standard of living } \\
\hline Medium/High & $48(81.4)$ & $70(64.2)$ & 1 & 5.38 \\
\hline Low & $11(18.6)$ & $39(35.8)$ & $2.43[1.07-5.61]$ & {$[0.020]$} \\
\hline \multicolumn{5}{|l|}{ Cooking fuel used } \\
\hline Gas & $44(74.6)$ & $55(50.5)$ & 1 & 9.20 \\
\hline Wood/Cow-dung & $15(25.4)$ & $54(49.5)$ & $2.88[1.36-6.14]$ & {$[0.002]$} \\
\hline \multicolumn{5}{|l|}{ Known diabetic } \\
\hline Yes & $55(93.2)$ & $103(94.5)$ & 1 & $0.00^{*}$ \\
\hline No & $4(6.8)$ & $6(5.5)$ & $0.80[0.19-3.55]$ & [0.994] \\
\hline \multirow{2}{*}{ Characteristics } & \multicolumn{4}{|c|}{ Uncorrected refractory error } \\
\hline & Urban $(\mathrm{N}=100)$ & Rural $(\mathrm{N}=150)$ & OR $[95 \% \mathrm{Cl}]$ & Chi square value [p value] \\
\hline \multicolumn{5}{|l|}{ Age in years } \\
\hline Upto 45 & $42(42)$ & $48(32)$ & 1 & 3.38 \\
\hline $46-60$ & $40(40)$ & $77(51.3)$ & $1.68[0.92-3.08]$ & {$[0.185]$} \\
\hline More than 60 & $18(18)$ & $25(16.7)$ & $1.22[0.55-2.70]$ & \\
\hline \multicolumn{5}{|l|}{ Sex } \\
\hline Male & $55(55)$ & $72(48)$ & 1 & 1.18 \\
\hline Female & $45(45)$ & $78(52)$ & $1.32[0.77-2.27]$ & {$[0.278]$} \\
\hline \multicolumn{5}{|l|}{ Standard of living } \\
\hline Medium/High & $85(85)$ & $106(70.7)$ & 1 & 6.84 \\
\hline Low & $15(15)$ & $44(29.3)$ & $2.35[1.17-4.76]$ & {$[0.009]$} \\
\hline \multicolumn{5}{|l|}{ Cooking fuel used } \\
\hline Gas & $86(86)$ & $112(74.7)$ & 1 & 4.68 \\
\hline Wood/Cow-dung & $14(14)$ & $38(25.3)$ & $2.08[1.01-4.33]$ & {$[0.031]$} \\
\hline \multicolumn{5}{|l|}{ Known diabetic } \\
\hline Yes & $34(34)$ & $61(40.7)$ & 1 & 1.13 \\
\hline No & $66(66)$ & 89 (59.3) & $0.75[0.43-1.32]$ & {$[0.287]$} \\
\hline
\end{tabular}

(Figures in parenthesis indicate percentages); * Yates' corrected

(No subject upto 15 years age had cataract and only one in urban area had uncorrected refractory error)

probably because they studied people aged more than 40 years of age as study subjects. Another study conducted by Dandona et al (2002) in Andhra Pradesh state showed an overall prevalence of cataract as $39.9 \% .^{6}$

In Malaysia a study conducted by Zainal et al (2002) showed the prevalence of Pterygium was $1.6 \%$ among urban Malaysian population, ${ }^{9}$ and present study showed prevalence of Pterygium was $3.6 \%$ in urban population. In India a study conducted by Singh et al (1997) showed the prevalence of Pterygium was $5.2 \%$ in rural Indian population, ${ }^{10}$ and present study showed prevalence of Pterygium was $2.4 \%$ among rural population.

A statistically significant association was found between low standard of living and wood or cow-dung fuel with cataract and refractory error in the present study, particularly in rural area. This may be because individuals residing in rural areas are mostly agricultural labourers or construction workers leading to more exposure to the UV-rays and majority of the females in rural areas use cow-dung ${ }^{11}$ and wood as cooking fuel which produce more smoke resulting in solidification of lens protein which may lead to cataract.

\section{CONCLUSION}

Prevalence of uncorrected refractory error and cataract remains high in the present study and especially in the rural area. Prevalence of other selected eye diseases was low among study population. Low standard of living and use of wood or cow-dung as cooking fuel proved as risk 
factors for both cataract and refractory error. This study reiterates the need of frequent ophthalmic screening and health education programme regarding risk factors towards blindness prevention among general population.

\section{ACKNOWLEDGEMENT}

We are thankful to all the study participants towards their co-operation for the present study. Authors also acknowledge all the ophthalmic assistants for their full support during conduct of the present study.

\section{REFERENCES}

1. Deshpande M. Vision 2020: Right to sight-India. MJAFI 2008; 64(4): 302-3.

2. Blindness Control Society, Cuddalore District. [Online] January 13, 2009. [Accessed on 25 March 2009] Available from URL:http://cuddalore.nic.in/ blindness.htm
3. Ophthalmic research in ICMR. [Online] December 27, 2007. [Accessed on 9 February 2008] Available from URL: http://www.icmr.nic.in/oph-icmr.pdf

4. Wright DJ. The Worldwide challenge of preventable blindness: International Glaucoma Association. [Online] January 10 2004. [Accessed on 7 March 2011] Available at URL:http://www.glaucomaweb.org/displaycommon. cfm?an $=10$

5. World Health Organization. Estimation of global visual impairment due to uncorrected refractive error. Bull World Health Organ. 2008; 86:8:B-C.

6. Dandona R, Dandona L, Srinivas M, Giridhar P, Prasad MN, Vilas K, McCarty CA, Rao GN. Moderate visual impairment in India: the Andhra Pradesh Eye Disease Study. Br J Ophthalmol. 2002; 86(4):373-7.

7. Haq I, Khan Z, Khalique N, Amir A, Jilani FA, Zaidi M. Prevalence of common ocular morbidities in adult population of Aligarh. Indian J Community Medicine. 2009; 34(3):195-201.

8. Thulasiraj RD, Nirmalan PK, Ramakrishnan R, Krishnadas R, Manimekalai TK, Baburajan NP, Katz J, Tielsch JM, Robin AL. Blindness and vision impairment in a rural South India population: the Aravind Comprehensive Eye Survey. Ophthalmology. 2003; 110(8):1491-8.

9. Zainal M, Ismail SM, Ropilah AR, Elias H, Arumugam G, Alias D, Fathilah J, Lim TO, Ding LM, Goh PP. Prevalence of Blindness and Low Vision in Malaysian Population. Br J Ophthalmol 2002; 86(9):951-6.

10. Singh MM, Murthy GV, Venkatraman R, Rao SP, Nayar S. A study of ocular morbidity among elderly population in rural area of central India. Indian $\mathrm{J}$ Ophthalmol. 1997; 45(1):61-5.

11. Pakhetra R, VP Jyotsna. Bilateral early cataracts in Type I diabetes. MJAFI 2009; 65: 71-2. 